\title{
Heparin Binding Protein and Endothelial Glycocalyx Markers in Severe COVID-19 - A Prospective Observational Cohort Study
}

\section{Lisa Mellhammar ( $\square$ lisa.mellhammar@med.lu.se)}

VO Infektion, Skånes Universitetssjukhus, 20520 Malmö, Sweden

Louise Thelaus

Lunds universitet Medicinska fakulteten

Sixten Elén

Lunds universitet Medicinska fakulteten

Jane Fisher

Lunds universitet Medicinska fakulteten

Adam Linder

Lunds universitet Medicinska fakulteten

\section{Research}

Keywords: COVID-19, Heparin binding protein, biomarkers, sepsis

Posted Date: September 9th, 2020

DOI: https://doi.org/10.21203/rs.3.rs-64087/v1

License: (c) (i) This work is licensed under a Creative Commons Attribution 4.0 International License. Read Full License 


\section{Abstract}

\section{Background:}

The pathophysiology of severe COVID-19 has been implicated to involve neutrophil activation in the blood and in the lungs and endothelial dysfunction.

Heparin binding protein (HBP) is a neutrophil protein that plays an important role in bacterial sepsis and is a promising biomarker in severe infections. Syndecans and glypicans are potential markers of sheeding of the glycocalyx and endothelial dysfunction.

The primary aims of this study were to assess whether HBP or syndecans and glypicans are involved in the pathophysiology of COVID-19 and if so, whether they can be used to predict severe disease preferably using a point-of-care test (POC) that can substitute more time-consuming analysis with enzyme-linked immunosorbent assay (ELISA).

Methods: A prospective convenience sample study of biomarkers. The main cohort consisted of patients admitted to hospital with a confirmed COVID-19 diagnosis. Samples and clinical data were collected at admission, during admission and at discharge and samples were analyzed with ELISA kit (Axis-Shield Diagnostics) for measuring HBP concentration and a novel dry immunofluorescence analyzer (Jet-iStar 800) (Joinstar) for point-of-care testing.

Results: Thirty-five COVID-19 patients were prospectively enrolled in the study. HBP was significantly elevated in COVID-19 patients with organ dysfunction $(n=23)$ compared to those without organ dysfunction ( $\mathrm{n}=6), 24.7 \mathrm{ng} / \mathrm{mL}(95 \% \mathrm{Cl} 17.3-48.4)$ vs $10.6 \mathrm{ng} / \mathrm{mL}(95 \% \mathrm{Cl} 6.2-17.1 \mathrm{ng} / \mathrm{mL}), p=0.03$. Syndecan-1 and Glypican-4 were not significantly elevated in patients with organ dysfunction. Syndecan$1,62.1 \mathrm{ng} / \mathrm{mL}$ (44.4-102.0) vs $57.5 \mathrm{ng} / \mathrm{mL}$ (95\% Cl 46.0- 63.7), $p=0.44$ and glypican-4, $3292.4 \mathrm{pg} / \mathrm{mL}$ (95\% Cl 1707.5- 6790.6) vs $3962.7 \mathrm{pg} / \mathrm{mL}$ (95\% Cl 2653.6- 5823.5), $p=0.80$. The point-of-care (POC) HBP test showed good correlation to the standard ELISA with an R-value of 0.83. HBP measured by the POC device predicted development of COVID-induced organ dysfunction within 72 hours with an AUC of 0.88 .

Conclusions: The neutrophil-derived HBP is elevated prior to onset of organ dysfunction in patients with severe COVID-19 using a newly developed point-of-care test and hence HBP could be used in a clinical setting as a prognostic marker in COVID-19.

\section{Introduction}

By August 16th, the number of confirmed cases of coronavirus disease (COVID-19) are more than 21 million worldwide (1). Most patients experience a mild illness, although $5 \%$ develop sepsis (2). Sepsis is most often caused by bacteria, but the majority of COVID-19 patients do not have a bacterial superinfection (3). Sepsis is a heterogenous disease and the pathophysiology of sepsis due to COVID-19 is elusive. 
Neutrophils are a key player in bacterial sepsis, but their role in viral sepsis is less well defined (4). Patients with severe COVID-19 tend to have elevated numbers of neutrophils in the blood and in the lungs, suggesting that they might be involved in COVID-19 pathophysiology $(5,6)$. Heparin binding protein (HBP) is a neutrophil protein that plays an important role in bacterial sepsis (7). HBP is stored in the secretory vesicles and azurophilic granules of neutrophils and released upon activation (7). Because it is pre-fabricated and released early during infections, HBP is a promising biomarker in severe infections. Plasma HBP levels are elevated up to 12 hours before the first signs of circulatory failure and organ dysfunction appear in patients with sepsis (8). HBP is also a strong inducer of endothelial barrier dysfunction and inflammation, and predicts lung and kidney dysfunction in patients with sepsis and septic shock (9-11). Although best studied in bacterial infections, elevated HBP levels have been found in some severe viral infections including Influenza A (H1N1) and COVID-19 $(12,13)$.

Several studies have suggested that the SARS-COV-2 virus might disproportionately affect endothelial cells and that pre-existing endothelial damage due to aging, cardiovascular diseases or diabetes mellitus could lead to more severe COVID-19 (14-17). A crucial component of the endothelium is the glycocalyx, a complex matrix on the cell surface composed of proteins and glycans $(18,19)$. Proteoglycans such as syndecans and glypicans are major components of the glycocalyx, and are shed from the endothelium during sepsis and other critical illnesses (20-24). It is not known whether the glycocalyx is affected during severe COVID-19.

The primary aims of this study were to assess whether HBP can predict sepsis in COVID-19 and if pointof-care (POC) testing can substitute more time-consuming analysis with enzyme-linked immunosorbent assay (ELISA). We also aimed to determine whether endothelial glycocalyx dysfunction occurs, and whether the plasma glycocalyx markers syndecan- 1 and glypican- 4 are also associated with sepsis in COVID-19.

\section{Materials And Methods}

\section{Sample and clinical data collection}

Patients admitted to the clinic of infectious diseases at Skane University Hospital (Lund, Sweden) with a confirmed COVID-19 diagnosis were enrolled prospectively in a convenience study of biomarkers, referred to as the "COVID-19 cohort". Ethical approval was obtained from the regional ethical review boards (permission no. 2016/39). EDTA-blood was collected from 35 patients and processed with centrifugation for 10 minutes at $2000 \mathrm{xg}, 60$ minutes within collection. Plasma was separated and stored until further analysis at $-80^{\circ} \mathrm{C}$. Samples were collected at admission, during admission and at discharge. We used the highest HBP value measured in the first 72 hours after admission for prediction of organ dysfunction.

For comparison to bacterial sepsis and other viral sepsis, two cohorts of patients originally enrolled for prospective multicenter studies of biomarkers were used. In the first cohort, patients were included if $\geq$ 18 years and suspected sepsis i.e. with fever or history of fever and highest priority according to Rapid 
Emergency Triage System (RETTS) or lactate $>3.5 \mathrm{mmol}$ at Skåne University Hospital in Lund between April 2017 and February 2018 and plasma samples was collected at ED admission (unpublished).

Patients that had a positive blood culture for bacteria and fulfilled the sepsis-3 criteria were included in this study why this cohort is referred to as the "bacterial sepsis cohort" (25). In the cohort referred to as the "viral sepsis cohort", plasma samples from all patients with PCR-verified viral infections other than COVID-19 were collected from a cohort with ED patients included if $\geq 18$ years with at least one of: respiratory rate $>25$ breaths/minute, heart rate $>120$ beats/minute, altered mental awareness, systolic blood pressure below $100 \mathrm{mmHg}, \mathrm{SpO} 2<90 \%$, or $<93 \%$ if ongoing oxygen treatment. Ethical approvals were given under permission no. 2014/741 and 2016/39, respectively.

Data on comorbidities, organ dysfunction, treatment, intensive care and mortality were collected from medical records. Organ dysfunction was defined as a change in sequential organ failure assessment (SOFA) score of $\geq 2$ at any time during admission.

\section{Analysis of biomarkers}

\section{ELISA}

ELISA kit for measuring HBP concentration was purchased from Axis-Shield Diagnostics. Recommended dilutions of 1:40 was used for all plasma samples unless samples was found outside the range of the standard curve, in which case the samples were diluted further.

Endothelial glycocalyx components, glypican-4 and syndecan-1 (CD138), were measured with purchased kits from Cloud-Clone Corp and Diaclone respectively. Samples were diluted 1:1 for the syndecan assay and 1:10 for the glypican assay.

\section{Point-of-care (POC) assay}

Additionally, we validated a novel Dry Immunofluorescence Analyzer (Jet-iStar 800) (Joinstar) for rapid detection of HBP, which is based on immunoassay technology. This rapid test gives a result within 20 minutes and could be a more convenient method for clinical measurement of HBP, and therefore we also measured HBP concentrations in COVID-19 plasma samples using this assay.

With the aim to assess some of the key analytical performances of the HBP POC assay, a validation in multiple steps was performed. Accuracy was tested by measuring repeated samples with the same concentration. The lower limit detection was tested by measuring replicates of purified water. Linearity was tested using a dilution series of samples with known high and low concentrations. Finally precision was tested by measuring replicates of the provided control samples with known HBP concentrations. For detailed methods and results of validation, see additional file 1 and additional Fig. 1.

\section{Statistical analysis}


Independent, continuous variables are presented as median with interquartile ranges (IQR) and were analyzed with corrections for multiple comparisons using Kruskal-Wallis test with Dunn's post-hoc test for multiple comparisons when more than three variables were present, or Mann-Whitney test when two variables were analyzed. Receiver operating characteristic (ROC) curves and the area under the curve (AUC) were generated to determine the predictive value of HBP (highest measured value 72 hours from admission) for development of organ dysfunction at any time during hospital stay. Statistical analyses and graphs were performed using GraphPad Prism version 8.3.1. A $p$-value $<0.05$ was considered statistically significant.

\section{Results}

Thirty-five patients were enrolled in the COVID-19 cohort. Twenty-four and 28 patients were included in the bacterial sepsis cohort and viral sepsis cohort, respectively.

First, HBP concentration on admission was compared in patients with COVID-19, patients with confirmed bacteremia and sepsis and patients with confirmed non-COVID viral infection to determine if there was any elevation in COVID-19 patients. Patients within each cohort were divided into two groups based on whether they developed organ dysfunction at any time. Patients characteristics for each cohort are presented in Table 1. HBP was elevated in COVID-19 patients with onset of organ dysfunction $(n=23)$ compared to those without $(\mathrm{n}=6), 24.7 \mathrm{ng} / \mathrm{mL}(95 \% \mathrm{Cl} 17.3-48.4)$ vs $10.6 \mathrm{ng} / \mathrm{mL}(95 \% \mathrm{Cl} 6.2-$ $17.1 \mathrm{ng} / \mathrm{mL}$ ), $p=0.03$, while there was no difference between those who developed organ dysfunction ( $\mathrm{n}$ $=20)$ and those who did not $(\mathrm{n}=8)$ in the viral sepsis cohort, $11.0 \mathrm{ng} / \mathrm{mL}(95 \% \mathrm{Cl} 5.2-19.7) \mathrm{vs}$ $13.4 \mathrm{ng} / \mathrm{mL}(95 \% \mathrm{Cl} 6.7-16), p=0.10)$ (Fig. 1A).

In the COVID-19 cohort, glypican-4 and syndecan-1 were measured in plasma to determine the level of glycocalyx shedding. There were no significant differences in levels of either glypican-4, $3292.4 \mathrm{pg} / \mathrm{mL}$ (95\% Cl 1707.5- 6790.6) vs $3962.7 \mathrm{pg} / \mathrm{mL}$ (95\% Cl 2653.6- 5823.5), $p=0.80$, nor syndecan-1, $62.1 \mathrm{ng} / \mathrm{mL}$ (44.4-102.0) vs $57.5 \mathrm{ng} / \mathrm{mL}(95 \% \mathrm{Cl} 46.0-63.7), p=0.44$, in patients who developed organ dysfunction compared to those who did not (Fig. 1B-C).

Because we found that HBP levels were elevated in patients who later developed organ dysfunction, we explored the hypothesis that HBP can predict organ dysfunction in patients with COVID-19. Because the POC test has the potential for immediate clinical use, we compared the HBP ELISA with the Joinstar POC and found good correlation with and R-value of 0.83 (Additional Fig. 1). For the further analysis of HBPs prognostic capacity, we then used HBP values measured by the Joinstar POC test since this would be more clinically relevant. ROC curve, using the highest HBP value in the first 72 hours, showed an AUC of 0.88 (95\% Cl 0.70-1.0) $p<0.01$ for HBP in predicting 72 hour development of organ dysfunction (Fig. 2A). Next, to determine the dynamics of HBP during the course of COVID-19, we compared HBP levels in samples taken at admission, within 48 hours before onset of organ dysfunction, and before discharge from hospital. We found that HBP was significantly elevated before the onset of organ dysfunction 
compared to admission samples $19.0 \mathrm{ng} / \mathrm{mL}$ (95\% Cl 10.8-33.1) vs $7.6 \mathrm{ng} / \mathrm{mL}(5.9-14.9), p=0.01)$. Before discharge from hospital median HBP was reduced to $9.0 \mathrm{ng} / \mathrm{mL}$ (5.9-12.8), $p=0.05$ (Fig. 2B).

Table 1

Characteristics of included patients

\begin{tabular}{|llll|}
\hline & $\begin{array}{l}\text { COVID-19 } \\
\mathbf{n = 3 5}(\%)\end{array}$ & $\begin{array}{l}\text { Bacterial sepsis } \\
\mathbf{n}=\mathbf{2 4}(\%)\end{array}$ & $\begin{array}{l}\text { Viral sepsis } \\
\mathbf{n}=\mathbf{2 8}(\%)\end{array}$ \\
\hline Baseline characteristics & & & \\
\hline Sex (female) & $12(35)$ & $11(46)$ & $15(54)$ \\
\hline Age (median) & $63(52-76)$ & $74(71-79)$ & $71(64-84)$ \\
\hline Comorbidities & & & \\
\hline Diabetes mellitus & $4(11)$ & $5(21)$ & $4(14)$ \\
\hline Cardiovascular disease & $12(34)$ & $12(50)$ & $9(32)$ \\
\hline Renal disease & $4(11)$ & $3(13)$ & $6(11)$ \\
\hline Respiratory disease & $5(14)$ & $4(17)$ & $5(18)$ \\
\hline Malignancy & $1(3)$ & $4(17)$ & 2 \\
\hline Clinical characteristics & & & $3(11)$ \\
\hline SOFA increase< $72 \mathrm{~h}$ (median) & 2 & 2 & $0(0)$ \\
\hline Critical care & $3(9)$ & $5(21)$ & $2(7)$ \\
\hline Mechanical ventilation & $2(6)$ & $2(8)$ & $0(0)$ \\
\hline Vasopressor & $2(6)$ & $5(21)$ & $1(0)$ \\
\hline Acute dialysis & $1(3)$ & $2(8)$ & \\
\hline Mortality (in-hospital) & $2(6)$ & & \\
\hline SoFA, Sequential Organ Failure Assessmen & & & \\
\hline
\end{tabular}

\section{Discussion}

Our results show that the neutrophil-derived HBP, a potent inducer of endothelial dysfunction, is elevated prior to onset of organ dysfunction in patients with severe COVID-19. However, glypican-4 and syndecan-1 are not elevated in patients with COVID-19, indicating that glycocalyx shedding is not greatly affected during severe COVID-19.

This study validates the findings of Saridaki et al. that also found HBP levels to be increased in severe COVID-19 and to correlate to poor outcome (13). 
Our study adds important information on both the prognostic potential and the use of a POC test, indicating great potential for clinical use in the near future. Earlier sepsis prediction, detection and diagnostics are important to enable early treatment and adequate care of patients. In an epidemic situation this is also important for triage of patients in need of health care resources. We found that HBP predicts the onset of sepsis and organ dysfunction in COVID-19, when measured by a POC device. POC testing can allow for rapid measurement of HBP within 20 minutes, and therefore is available for immediate clinical application and may provide the clinician with timely and important clinical information.

Our results add to a growing body of evidence that neutrophil activation is an important part of COVID-19 pathophysiology and might be a reason why the clinical phenotype of severe COVID-19 have common features with bacterial sepsis (26). Bacterial superinfections are relatively uncommon in COVID-19, with less than $10 \%$ of included patients in our cohort having positive bacterial cultures. Therefore, the elevated HBP levels in this cohort cannot be explained by the presence of bacterial infections and must be caused by the viral infection itself.

Previous studies have indicated that HBP plays a causative role in different sepsis-induced organ dysfunctions, by inducing inflammation in kidney cells and by inducing vascular leakage which leads to lung dysfunction. It is also possible that HBP plays a causative role in the onset of organ dysfunction in COVID-19, and therefore it may be a possible therapeutic target. Heparin is a potent inhibitor of many of the detrimental effects of HBP. Many hospitals now routinely administer low-molecular weight heparin (LMWH) to hospitalized COVID-19 patients to prevent clot formation. It is therefore possible that an offtarget benefit of heparin administration in COVID-19 is its interference with HBP.

Although we found elevated levels of HBP, a known inducer of endothelial dysfunction, and although COVID-19 is known to affect the endothelium, we failed to identify any evidence of glycocalyx shedding in this cohort. It is possible that COVID-19-induced endothelial dysfunction occurs through mechanisms that do not involve the glycocalyx. However, we did not measure plasma levels of other glycocalyx components such as GAGs and other proteoglycans, so we cannot rule out shedding of these components. Nor did we measure levels of any other endothelial damage markers, such as Intercellular Adhesion Molecule 1 (ICAM-1), and therefore we did not confirm the presence of endothelial damage in this cohort. It is also possible that these patients did not have high levels of endothelial damage.

The main strengths of this study include the measurement of HBP using two different methods, and our validation of a POC device for HBP which could give important and rapid information to the treating physician. Limitations of the study include the small cohort size and the heterogenous timing of plasma collection between patients. Additionally, the concomitant medications administered routinely changed during the enrollment period, with the addition of LMWH and the addition of corticosteroids. Due to the small cohort size, we were not able to use statistical methods to correct for the effects of these concomitant medications. 


\section{Conclusions}

We have shown that HBP is elevated prior to development of organ dysfunction using a newly developed POC test and hence HBP could be used in a clinical setting as a prognostic marker for pending organ dysfunction in COVID-19. Therefore, we suggest that a randomized controlled trial of HBP as a prognostic marker of organ dysfunction in COVID-19 is warranted.

\section{Declarations}

\section{Ethics approval and consent to participate}

The study was approved by the Regional Ethical Review Board in under permission no. 2014/41 and 2016/39.

Informed consent was obtained from all participants in the viral sepsis cohort. For patients in the COVID19 cohort and bacterial sepsis cohort we provided an opt-out method where patients received study information, contact details, a pre-printed letter of opt-out and a return envelope.

Consent for publication Not applicable

Availability of data and material Anonymised data from the study is available upon reasonable request.

\section{Competing interests}

Adam Linder is listed as an inventor on a patent on the use of HBP as a diagnostic tool in sepsis filed by Hansa Medical AB. All other authors have declared no relevant conflicts of interest.

\section{Funding}

Swedish Government Funds for Clinical Research (ALF), Region Skåne, the Crafoord foundation, the foundation of Alfred Österlund are acknowledged for generous support.

\section{Authors' contributions}

LM and AL had full access to all of the data in the study and takes responsibility for the integrity of the data and the accuracy of the data analysis.

Study concept and design: $\mathrm{AL}$

Acquisition, analysis, or interpretation of data: LM, LT, SE, JF

Drafting of the manuscript: $\mathrm{LM}, \mathrm{LT}, \mathrm{JF}, \mathrm{AL}$

Critical revision of the manuscript for important intellectual content: All authors 


\section{Acknowledgements}

Thank you to Joinstar and Anil Vasishta for providing the HBP point of care assay.

\section{References}

1. (WHO) WHO. Coronavirus disease 2019 (COVID-19): situation report. World Health Organization. 2020;209.

2. Guan W-j, Ni Z-y, Hu Y, Liang W-h, Ou C-q, He J-x, et al. Clinical Characteristics of Coronavirus Disease 2019 in China. N Engl J Med. 2020;382(18):1708-20.

3. Zhou F, Yu T, Du R, Fan G, Liu Y, Liu Z, et al. Clinical course and risk factors for mortality of adult inpatients with COVID-19 in Wuhan, China: a retrospective cohort study. The Lancet. 2020;395(10229):1054-62.

4. Galani IE, Andreakos E. Neutrophils in viral infections: Current concepts and caveats. J Leukoc Biol. 2015;98:4:557-64.

5. Wu C, Chen X, Cai Y, Xia J, Zhou X, Xu S, et al. Risk Factors Associated With Acute Respiratory Distress Syndrome and Death in Patients With Coronavirus Disease 2019 Pneumonia in Wuhan, China. JAMA Intern Med. 2020.

6. Barnes BJ, Adrover JM, Baxter-Stoltzfus A, Borczuk A, Cools-Lartigue J, Crawford JM, et al. Targeting potential drivers of COVID-19: Neutrophil extracellular traps. J Exp Med. 2020;217(6).

7. Fisher J, Linder A. Heparin-binding protein: a key player in the pathophysiology of organ dysfunction in sepsis. J Intern Med. 2017;281(6):562-74.

8. Linder A, Christensson B, Herwald H, Björck L, Akesson P. Heparin-Binding Protein: An Early Marker of Circulatory Failure in Sepsis. Clin Infect Dis. 2009;49:1044-50.

9. Fisher J, Russell JA, Bentzer P, Parsons D, Secchia S, Mörgelin M, et al. Heparin-Binding Protein (HBP): A Causative Marker and Potential Target for Heparin Treatment of Human Sepsis-Induced Acute Kidney Injury. Shock. 2017;48(3):313-20.

10. Bentzer P, Fisher J, Kong HJ, Mörgelin M, Boyd JH, Walley KR, et al. Heparin-binding protein is important for vascular leak in sepsis. Intensive Care Med Exp. 2016;4(1):33-.

11. Linder A, Arnold R, Boyd JH, Zindovic M, Zindovic I, Lange A, et al. Heparin-Binding Protein Measurement Improves the Prediction of Severe Infection With Organ Dysfunction in the Emergency Department. Crit Care Med. 2015;43(11):2378-86.

12. Kaukonen KM, Linko R, Herwald H, Lindbom L, Ruokonen E, Ala-Kokko T, et al. Heparin-binding protein (HBP) in critically ill patients with influenza $A(H 1 N 1)$ infection. Clin Microbiol Infect. 2013;19(12):1122-8.

13. Maria Saridaki SM, Sotiria Grigiropoulou E, Vrentzos M, Lada K, Argyraki O, Tsachouridou A, Georgiadou A, Vasishta, Giamarellos-Bourboulis EJ. Integration of heparin-binding protein and 
interleukin- 6 in the early prediction of respiratory failure and mortality in pneumonia by SARS-CoV-2 (COVID-19). Preprint at https://wwwresearchsquarecom. 2020.

14. Huertas A, Montani D, Savale L, Pichon J, Tu L, Parent F, et al. Endothelial cell dysfunction: a major player in SARS-CoV-2 infection (COVID-19)? Eur Respir J. 2020;56(1):2001634.

15. Amoretti M, Amsler C, Bonomi G, Bouchta A, Bowe P, Carraro $C$, et al. Production and detection of cold antihydrogen atoms. Nature. 2002;419(6906):456-9.

16. Froldi G, Dorigo P. Endothelial dysfunction in Coronavirus disease 2019 (COVID-19): Gender and age influences. Med Hypotheses. 2020;144:110015.

17. Varga Z, Flammer AJ, Steiger P, Haberecker M, Andermatt R, Zinkernagel AS, et al. Endothelial cell infection and endotheliitis in COVID-19. The Lancet. 2020;395(10234):1417-8.

18. Alphonsus CS, Rodseth RN. The endothelial glycocalyx: a review of the vascular barrier. Anaesthesia. 2014;69(7):777-84.

19. Reitsma S, Slaaf DW, Vink H, van Zandvoort MAMJ, oude Egbrink MGA. The endothelial glycocalyx: composition, functions, and visualization. Pflugers Arch. 2007;454(3):345-59.

20. Johansson PI, Stensballe J, Rasmussen LS, Ostrowski SR. A high admission syndecan-1 level, a marker of endothelial glycocalyx degradation, is associated with inflammation, protein C depletion, fibrinolysis, and increased mortality in trauma patients. Ann Surg. 2011;254(2):194-200.

21. Chelazzi C, Villa G, Mancinelli P, De Gaudio AR, Adembri C. Glycocalyx and sepsis-induced alterations in vascular permeability. Crit Care. 2015;19(1):26-

22. Nelson A, Johansson J, Tydén J, Bodelsson M. Circulating syndecans during critical illness. APMIS. 2017;125(5):468-75.

23. Fisher J, Linder A, Bentzer P. Elevated plasma glypicans are associated with organ failure in patients with infection. Intensive Care Med Exp. 2019;7(1):2-.

24. Chen $C$, Huang $X$, Ying Z, Wu D, Yu Y, Wang X, et al. Can glypican-3 be a disease-specific biomarker? Clin Transl Med. 2017;6(1):18.

25. Singer M, Deutschman CS, Seymour CW, Shankar-Hari M, Annane D, Bauer M, et al. The Third International Consensus Definitions for Sepsis and Septic Shock (Sepsis-3). Jama. 2016;315(8):801-10.

26. Zuo Y, Yalavarthi S, Shi H, Gockman K, Zuo M, Madison JA, et al. Neutrophil extracellular traps in COVID-19. JCl Insight. 2020.

\section{Figures}



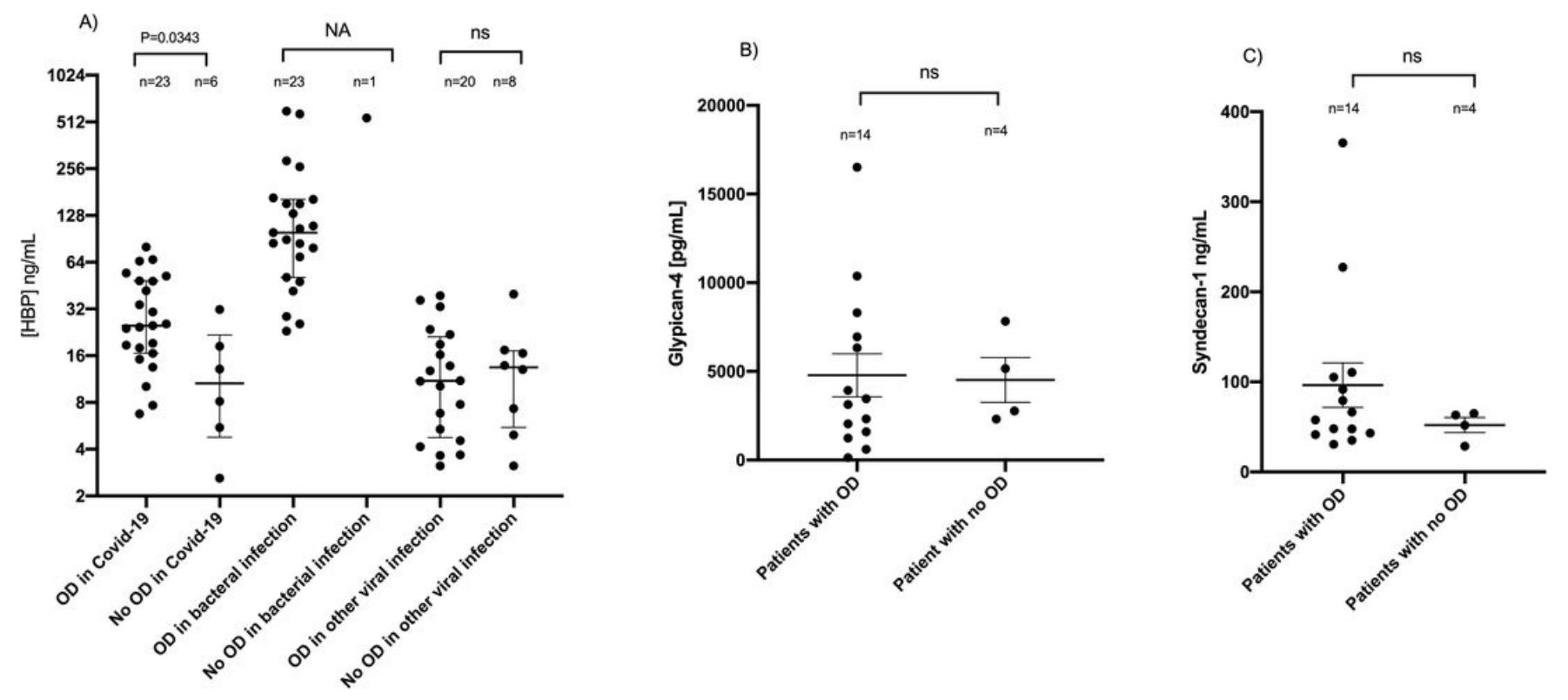

Figure 1

Concentration of HBP and glycocalyx markers in patients with severe COVID-19 and other sepsis (A) Plasma HBP levels measured with ELISA in patients with COVID-19, verified bacterial infection or other viral infection than COVID-19 with and without organ dysfunction (OD). Samples in the COVID-19 cohort are the highest value taken within the first 72 hours from admission. Samples in the bacterial and other viral cohorts were taken at admission. Values were compared using Kruskal Wallis test with Dunn's posthoc test for multiple comparisons. (B) Plasma glypican-4 levels in COVID-19 patients with and without organ dysfunction in samples taken within $72 \mathrm{~h}$ from admission (P-value $=0.7980$ ) (C) Plasma syndecan-1 levels in COVID-19 patients with and without organ dysfunction in samples taken within $72 \mathrm{~h}$ from admission ( $P$-value $=0.4418$ ). Values in $\mathrm{B}$ and $\mathrm{C}$ were compared using Mann Whitney test. 
B)

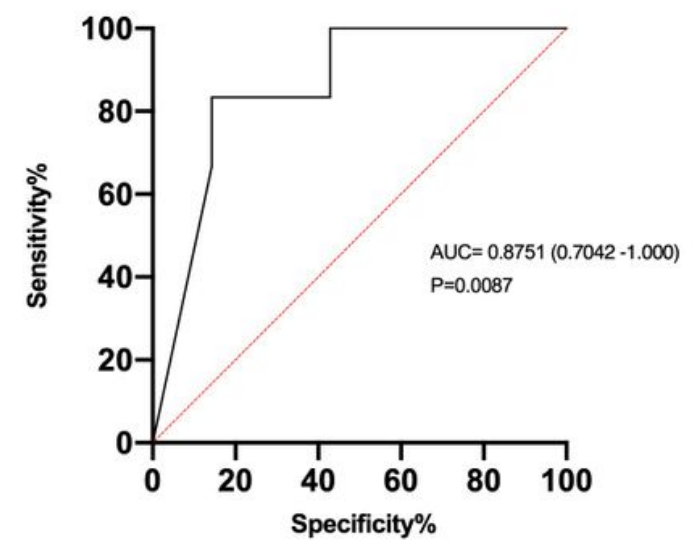

A)

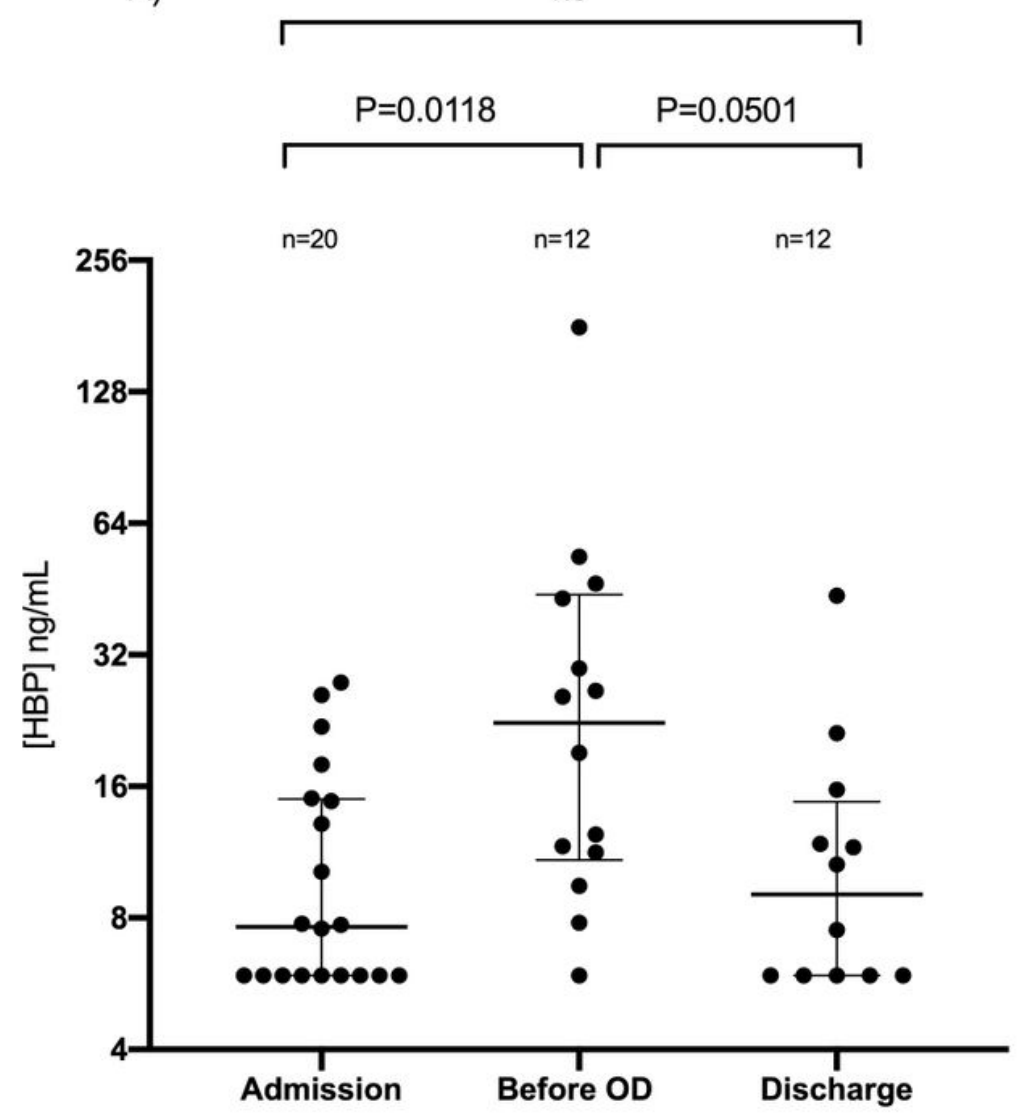

Figure 2

HBP prognosticates organ dysfunction in severe COVID-19. (A) A Receiver operating curve (ROC) of HBP measured by Joinstar POC test (highest value in the first 72h) predicting organ dysfunction (OD) in severe COVID-19. Area under the curve is 0.86. (B) HBP levels in first sample taken at admission, within 48h before development of organ dysfunction, and within $48 \mathrm{~h}$ before hospital discharge measured by the Joinstar POC test. Samples from patients who developed organ dysfunction within $48 \mathrm{~h}$ after admission were included in the "before OD" group instead of the "admission" group. Values were compared using Kruskal Wallis test with Dunn's post-hoc test for multiple comparisons A Receiver operating curve (ROC) of HBP measured by Joinstar POC test (highest value in the first 72h) predicting organ dysfunction (OD) in severe COVID-19. Area under the curve is 0.8571.

\section{Supplementary Files}

This is a list of supplementary files associated with this preprint. Click to download.

- Supplementmaterial.docx 
- Supplementfigure.tiff

Page 13/13 